\title{
Questions About In-Breast Tumor Recurrence in Patients Treated with Breast-Conserving Therapy
}

\author{
Kadri Altundag, MD \\ MKA Breast Cancer Clinic, Cankaya, Ankara, Turkey
}

\section{TO THE EDITOR}

I wish to congratulate Laird and colleagues for their article entitled "Impact of an in situ component on outcome after in-breast tumor recurrence in patients treated with breast-conserving therapy", in which they investigated the impact of an in situ component on outcome after in-breast tumor recurrence (IBTR) in 3932 patients treated with breast-conserving therapy (BCT). ${ }^{1}$ After exclusions, 81 patients with isolated IBTR comprised the study population. Laird et al. concluded that the presence of an in situ component is associated with prognosis among patients with IBTR following BCT and may be useful in differentiating true recurrences and new primaries; however, they did not report molecular subtypes of all 3932 primary tumors. Hormone receptor-positive ductal carcinoma in situ pathology may exist in some cases of triple-negative or human epidermal growth factor receptor 2 (HER2)-positive primary tumors. In these cases, the use of endocrine treatment for preventive measures might be plausible, although there is no consensus statement regarding this issue. It is also important to describe the molecular subtype of the primary tumor from which these 81 IBTRs developed.

\section{REFERENCE}

1. Laird J, Lok B, Siu C, et al. Impact of an in situ component on outcome after in-breast tumor recurrence in patients treated with breast-conserving therapy. Ann Surg Oncol. 2017. https://doi.org/ 10.1245/s10434-017-6209-4. 